\title{
O Idoso e a Internet: uma etnografia sobre interação e aprendizagem
}

Rafael Tezza

\begin{abstract}
Doutorando do Programa de Pós-Graduação em Engenharia de Produção da Universidade Federal de Santa Catarina
\end{abstract}

Antonio Cezar Bonia

\begin{abstract}
Mestre e Doutor em Engenharia de Produção.
Professor adjunto do Departamento de Engenharia de Produção e Sistemas da Universidade Federal de Santa Catarina
\end{abstract}

O idoso vem tendo seu primeiro contato com os sistemas de informação através da internet, e este contato envolve algumas particularidades. Este artigo explora a interação de um grupo de idosos com a Internet, abordando seus interesses, forma de aprendizagem, medos e dificuldades, por meio de uma etnografia que utiliza observação participante e entrevista em profundidade. O estudo demonstrou as peculiaridades no aprendizado deste grupo (aprendizagem por pares), os elementos geradores de interesse, as dificuldades e os medos envolvidos.

Palavras-chave: Internet; Interação; Idoso; Aprendizagem por pares.

\section{The elderly and the Internet: an ethnography about interaction and learning}

The elderly has been having their first contact with information systems through the Internet, and this contact involves some particularities. This article explores the interaction of a group of elderly people with the Internet, their interests and ways of learning, fears and difficulties, through an ethnography using participant observation and in depth interviews. The study showed the peculiarity of this group in learning (peer learning), the factors generating the interests, the difficulties and fears involved. 
Keywords: Internet; Interaction; Elderly; Peer learning

Recebido em 16.03.2009Aceito em 05.03.2010

\section{Introdução}

É importante considerar que a grande popularização da Internet nos dias de hoje se dá de maneiras diferentes em determinadas culturas, e até mesmo dentro das próprias culturas, nas chamadas sub-culturas e micro-culturas (McCURDY; SPRADLEY; SHANDY, 2005) e está relacionada com fatores sociais, econômicos e estruturais. Dentro dos fatores sociais, encontra-se o contexto cultural relacionado à interação com os sistemas de informação ou ambiente virtual/tecnológico, que pode apresentar características diferenciadas entre pessoas de uma mesma cultura, como é o caso do idoso, o qual recentemente tem tido seu primeiro contato com - ambiente virtual. A interação do idoso com a Internet assume peculiaridades em relação à interação dos não idosos, e isso tem relação direta com seus objetivos e suas histórias de vida. Alguns estudos indicam que o uso da informática e da Internet facilitam o apoio social ao idoso e estimulam o companheirismo entre eles (DIXON, 1997; WRIGHT, 2000; KANAYAMA, 2003).

Outro ponto considerável na relação idoso-informática/Internet é a questão do aprendizado que assume também necessidades diferenciadas. A preocupação mais relevante, segundo a Organização das Nações Unidas para a Educação, a Ciência e a Cultura (UNESCO, 2008), é a de que, quando as pessoas alcançam a idade adulta, já acumularam uma bagagem de conhecimentos e experiências que deve ser considerada como aprendizado prévio obtido com a experiência de vida. Nesse contexto, a aprendizagem por pares é defendida por alguns autores como uma forma de facilitar e incentivar a aprendizagem de adultos por utilizar uma interação aluno-aluno associadas a indivíduos que são similares em posição, idade e interesses, dinamizando desta forma o envolvimento de todos os participantes no planejamento e na realização de atividades (VYGOTSKY, 1984; THORNTON, 2005; SALES, 2007).

No entanto, poucas pesquisas têm focado a interação do idoso com a Internet e seu aprendizado. Todavia, esses estudos vêm se tornando cada vez mais necessários, uma vez que a sociedade como um todo está envelhecendo e, portanto, os idosos vêm se tornando um grande usuário dessa tecnologia.

Este artigo tem como objetivo descrever a experiência, o comportamento e a aprendizagem de usuários da terceira idade com a Internet, através de observação e descrição do ambiente de interação dos idosos com a Internet, assim como suas motivações, medos e dificuldade em relação à Internet, os relacionamentos e suas experiências.

\section{Metodologia}


Considerando que a interação entre idosos e informática está relacionada com comportamento, compartilhamento de conhecimentos e aprendizagem, ou seja, um contexto cultural que envolve experiências e interpretações destas experiências, optou-se por um estudo descritivo etnográfico baseado em observação participante e entrevista em profundidade.

Segundo Taylor e Bogdan (1997), na etnografia o pesquisador descreve o contexto não através de conceitos, mas através da descrição de eventos. A observação participativa foi realizada por um dos pesquisadores, e utilizou 13 horas de observação e cerca de 10 páginas de notas de campo. A entrevista em profundidade concentrou-se em um único idoso, que assume, no grupo, o papel de multiplicador e já está no projeto há cerca de dois anos. A escolha de apenas um entrevistado baseia-se em Van Maanen (1991) que argumenta que, na busca de bons informantes e de informantes chaves, convém concentrar os esforços ou a atenção em uma ou em poucas pessoas, visto que não se deve assumir que todos os informantes possuam o mesmo entendimento ou conhecimento sobre o ambiente. Desta forma, foram feitas duas entrevistas, sendo a primeira, presencial e com duração de 35 minutos e a segunda, através de um serviço de mensagens eletrônicas via Internet (popularmente chamado $\mathrm{MSN}^{\circledR}$ ), com duração de 90 minutos.

\section{Infocentro: descrição do ambiente}

O estudo foi realizado em parceria com um núcleo de estudos gerontológicos da Universidade Federal de Santa Catarina, chamado Núcleo de Estudos da Terceira Idade (NETI) que foi criado em 1983 com a finalidade de oferecer várias atividades e cursos direcionados aos idosos. O núcleo atende hoje cerca de 600 idosos. Nos últimos anos, partido do crescente interesse de alguns idosos em aprender informática, o núcleo criou, em 2003, o que eles chamaram de oficina de inclusão digital ou Infocentro, onde inicialmente, foram criadas duas equipes de estudo, cada uma com cerca de 10 idosos-aprendizes, que passaram a ter aulas de informática com duração de uma hora e meia, duas vezes por semana, durante um semestre. Os idosos que se destacaram neste período como interessados e dispostos a ensinar foram convidados a serem multiplicadores, iniciando-se assim um modelo de aprendizado por pares, onde idoso ensina idoso, que, segundo a idealizadora do projeto, facilita e acelera o aprendizado entre eles.

Atualmente, a oficina conta com cerca de 30 idosos aprendizes divididos em três turmas de 10, que têm aula duas vezes por semana com duração de uma hora em meia. Oito multiplicadores se revezam para que haja pelo menos dois em cada aula, além da coordenadora, que dá o suporte necessário quando preciso. É utilizado como material didático uma apostila elaborada pela coordenadora juntamente com seus alunos anteriores e que está em constante aprimoramento, com a finalidade de suprir as necessidades identificadas pelos próprios idosos. 
A sala é relativamente pequena, mas suficiente para comportar 12 computadores e uma mesa de centro. Os computadores estão dispostos por todo o perímetro da sala, um ao lado do outro, com os monitores virados para o centro. Está fixado na parede um mapa da sala e da localização de cada computador, juntamente com o nome de três alunos, isto porque existem três turmas e em cada turma um aluno usa sempre o mesmo computador. Existem também dois pequenos murais, onde estão fixadas fotos de ex-alunos na sala de aula ou trabalhando com 0 computador ou expondo seus trabalhos realizados.

Todos os alunos possuem mais de 60 anos de idade e são, em sua grande maioria, do sexo feminino (90\%). Há apenas três aprendizes e três idosos multiplicadores do sexo masculino. Todos são alfabetizados, mas existe bastante heterogeneidade em relação ao grau de escolaridade, assim como outras características, o que é muito comum na população de idosos.

\section{Descobrindo os elementos que geram o interesse}

Como aprendizes, os idosos trazem um conjunto diferente de motivações, expectativas e capacidades para desempenhar as atividades de seu interesse. Além disso, querem opinar no modo de aprender e decidir até onde vai à atividade de aprendizagem (THORNTON, 2005).

Os idosos que fazem parte da oficina passaram por uma seleção no início do semestre que contava com cerca de noventa inscritos, dos quais menos de um terço teve efetivamente a oportunidade de participar das oficinas do corrente semestre. Segundo um dos multiplicadores, isso demonstra o crescente interesse dos idosos pela Internet. A grande maioria (80\%) deles mora longe da universidade, o que os obriga a dependerem de alguma condução, que, em grande parte, é o transporte coletivo. Alguns chegam a pegar quatro ônibus para assistirem a uma aula.

No primeiro contato com a turma, ou seja, no primeiro dia de observação, o pesquisador chegou à sala meia hora antes. A coordenadora, com quem foi feito o primeiro contato via telefone não havia chegado ainda. Desta forma, decidiu esperar no corredor, onde já havia duas alunas esperando o inicio da aula. Sem que elas soubessem quem ele era e quais suas intenções até então, sentou-se em uma cadeira próxima delas. Elas discutiam sobre as tarefas da aula anterior, na qual foi solicitado que respondessem um questionário. O pesquisador percebeu um grande interesse em trocar conhecimentos entre elas. Em poucos minutos, chegaram outras duas alunas, uma delas cumprimentou-o, houve então uma pausa no assunto anterior e passaram a falar de uma queda que uma delas havia sofrido, sem muita gravidade. Porém, logo em seguida voltaram a discutir o questionário. A maior dúvida era como conceituar a ação de salvar, o pesquisador teve a impressão de que todas sabiam para que serve a função e até como fazê-la no computador, mas elas queriam precisão na resposta e houve uma troca interessante de conhecimentos e experiências. Uma delas comentou que estava tomando 
gosto pela coisa, e que havia praticado no fim de semana, uma vez que, devido ao mau tempo, a viagem que ela e o marido haviam planejado não pôde ser feita, e então ela resolveu dedicar seu tempo à prática de informática. O pesquisador presenciou estas conversas por mais ou menos 15 minutos, pois foi neste tempo que a coordenadora chegou, cumprimentou todas as alunas que aguardavam. Neste momento, o pesquisador pode ouvir várias expressões de carinho de todas as alunas para com ela. Na seqüência, ela chamou-o para entrar na sala. Estavam na sala, além dos dois, duas multiplicadoras e um multiplicador, todos exalunos do curso. Normalmente, eles chegam minutos antes para discutir e planejar o que será visto em aula. O pesquisador foi apresentado pela coordenadora como um pesquisador que estaria ai para realizar observações da aula. E foi muito bem recebido pelos três multiplicadores.

Um dos multiplicadores justificou-me seu interesse pela informática:

"o idoso, atualmente, sente-se excluído no meio profissional e social, uma vez que constantemente solicitam-nos o nosso email, pesquisa na internet, ou seja, vários tipos de troca de informação pela internet. O maior interesse em minha opinião é pela internet, o fato de poder comunicar-se com quem está longe, vê-lo na webcam..." (MULTIPLICADOR A).

Este multiplicador é um agente público aposentado e tem um filho que mora em outro estado, com quem se comunica diariamente pelo serviço de mensagem eletrônica $\mathrm{MSN}^{\circledR}$. O pesquisador tomou por rotina chegar alguns minutos antes das aulas para ouvir os multiplicadores falarem entre si e, muitas vezes, com ele. Em uma dessas oportunidades, chegou vinte minutos antes e um dos multiplicadores já estava na sala lendo a apostila. Foi bem recebido e não demorou para que ele iniciasse uma conversa, falando, principalmente de seu filho que está longe. Em alguns minutos chegou outra multiplicadora, espontânea, sente-se a vontade com sua presença. De repente, ela começou a falar de sua satisfação de ser multiplicadora:

"sempre quis fazer trabalho voluntário, trabalhei com alfabetização de adultos por um tempo, mas não era o que eu queria. Fui convidada para trabalhar com doentes no hospital, em clinicas de repouso (...), mas não é uma coisa pra mim, me envolvo emocionalmente. Trabalhar com informática aqui me é gratificante e gosto muito. Eu já sabia utilizar informática antes mesmo de fazer o curso de capacitação de multiplicadores aqui no infocentro, mas tenho aprendido bastante aqui também" (MULTIPLICADOR B).

Outro multiplicador comentou empolgado: "no semestre passado tínhamos uma aluna de 88 anos" (MULTIPLICADOR C).

$\mathrm{O}$ interesse move o aprendizado e o maior interesse dos alunos que procuram o curso é a Internet "tanto para pesquisa, consulta, 
mas muito mais pelos e-mails e $M S N^{\circledR \prime \prime}$ (MULTIPLICADOR B), afirma uma das multiplicadores.

No final de uma das aulas que, pelo cronograma, antecedia a introdução à internet, a comunicação de que a próxima aula seria o primeiro acesso a internet causou muitas reações positivas e empolgadas.

Pelo fato de serem "iguais", com as mesmas afinidades e interesses, a troca de experiências é empolgante. Ao saber, pelo multiplicador, o que pode ser encontrado na Internet, eles ficam fascinados.

No inicio da primeira aula sobre Internet, em meio à leitura da apostila, a multiplicadora relatava algumas experiências com a Internet, como a em que ela e seu marido não sabiam o significado de uma determinada palavra, procuraram no Google ${ }^{\circledR}$ e encontraram. Todos os alunos ficaram encantados. Ao iniciar a primeira pesquisa na Internet, com o tema proposto "ervas medicinais", muitos deles entram no primeiro link que aparece, outros esperam o multiplicador antes de fazer qualquer ação, alguns se limitam à página inicialmente pesquisada, outros já entram em outras páginas de seu interesse (além do assunto "plantas medicinais"). O maior interesse foi mesmo por plantas medicinais e complementares. Duas alunas acessaram, independentemente, o site globo.com/maisvoce. Uma delas quis ver o programa ao vivo (não conseguiu, pois achou o site confuso) e duas alunas entraram em sites de notícias.

A maioria dos alunos entrou no curso sem saber sequer ligar o computador. Ao final da aula, uma das alunas chamou o pesquisador e disse, com orgulho: "eu e ela - apontando para a colega ao lado - quando chegamos aqui, não sabíamos nem ligar o computador. Hoje, olhe só o que já estamos fazendo" (APRENDIZ A). O início das aulas a que ela se refere foi há dois meses atrás.

Outra aluna comenta: "hoje vou treinar em casa" (APRENDIZ B).

O interesse principal, como pôde ser verificado, é aprender a utilizar a Internet, que, além da curiosidade intrínseca, está diretamente relacionado com três fatores chave, que potencializam e geram esse interesse e podem ser visualizados na Taxonomia 1.

\begin{tabular}{|l|l|}
\hline \multirow{2}{*}{ Tipos de Interesse } & Social \\
\cline { 2 - 2 } & Profissional \\
\cline { 2 - 2 } & Familiar \\
\hline
\end{tabular}

TAXONOMIA 1 - tipos de interesse

O interesse social relaciona-se com a possibilidade de inclusão digital. O interesse profissional diz respeito à independência em trabalhos rotineiros ou até mesmo em algum trabalho extra que o idoso possa se envolver. $O$ interesse familiar reside em acompanhar os integrantes mais jovens e facilitar a comunicação entre eles, bem como para mostrar aos familiares que ele, como idoso, é capaz de acompanhar a evolução tecnológica.

Em um estágio seguinte ao interesse inicial, há os tipos de envolvimento existentes na interação de aprendizagem da Internet 
(Taxonomia 2). Primeiramente, há o envolvimento intrapessoal - o idoso trata da sua individual interação com a internet, gerando a "identificação" com a máquina - o que é fundamental para manter-se o interesse e a continuidade do processo. Na etapa seguinte, há o envolvimento interpessoal, na qual o idoso não se limita aos seus interesses de "identificação" com a máquina e passa a sentir prazer em ajudar na "identificação" dos demais colegas, podendo-se chegar ao estágio máximo de envolvimento capaz de multiplicar conhecimentos e experiências, o que possibilita que o idoso se torne um multiplicador.

\begin{tabular}{|l|l|}
\hline \multirow{2}{*}{ Tipos de Envolvimento } & Intrapessoal \\
\cline { 2 - 2 } & Interpessoal \\
\hline
\end{tabular}

TAXONOMIA 2 - Tipos de envolvimento

Outro agente gerador de interesse identificado foram os jogos online, o que remete a um interesse por diversão, como pode ser verificado em trechos de uma das entrevistas:

"A Internet é uma atividade muito interessante, pois possibilita variedade de atividade, assim como jogos on line. (...) eu jogo bastante, Dominó on line, com todo o Brasil, no Banan Games, Paciência. Estes jogos são em dupla, do dominó, então se escolhe o parceiro e se joga em quatro pessoas. É muito . Já ganhamos e já perdemos. (...) lá no Infocentro não conseguimos abrir jogos on line. Acho que está bloqueado. Mas seria muito interessante que fosse incluído no currículo, pois é uma atividade que o idoso adora fazer. Por isso não ensinamos a eles. Vão ter que aprender a vasculhar ou perguntar a terceiros como eu fiz. (...) É que eu gosto de jogar cartas. O Free Cell foi o jogo que me identifiquei mais, pois quando não consigo jogar o dominó, vou para as cartas e me esqueço da vida, pois é jogo individual." (MULTIPLICADOR D)

\section{Passo a passo: a aprendizado}

Segundo um dos multiplicadores, no primeiro dia, mostra-se como funciona o computador internamente, e a aula é ministrada por um professor do departamento do INE. De acordo com esse mesmo multiplicador, é explicado cada componente do computador, por ser muito importante para que se tenha noção, ao menos superficial, do que está por trás dessa máquina. A coordenadora encara essa aula como o primeiro contato de desmistificação da máquina porque, segundo ela, a maioria dos alunos não tem a mínima noção de como funciona um computador e isso gera vários medos, entre eles, de danificar a máquina por não se saber utilizá-la.

O curso concentra-se na aprendizagem de editores de texto (Microsoft Word) para treinar a escrita digital, um editor de imagens (Microsoft Paint) para auxiliar na motricidade e, conseqüentemente, na 
habilidade com o mouse. Essas habilidades são a base para utilização da Internet, que é ensinada na seqüência.

O aprendizado não se limita à interação multiplicador/aprendiz. Não é raro se observar um colega auxiliando a outro, de forma bastante interessada.

A impressão que se tem é de um ambiente descontraído, onde, além de conhecimentos de informática, são compartilhados outros conhecimentos de vida. Alguns dos alunos chamam o multiplicador algumas vezes de monitor, outras de multiplicador e, na maioria das vezes, pelo nome mesmo. Segundo a coordenadora, o termo que melhor se aplica a essas pessoas é multiplicador e não monitor que, no caso deles, pode parecer "menos" do que de fato são, pois têm uma história de vida que os torna multiplicadores de conhecimento.

Ao iniciarem as tarefas, o auxílio não é exclusivo dos multiplicadores: os próprios alunos se ajudam entre si conforme suas afinidades. Segundo a idealizadora do projeto, foi exatamente esta atitude que lhe sugeriu a exploração do método de aprendizagem por pares, pois ela percebia que, enquanto ela ensinava um aluno, outros pediam ajuda a outros alunos e esta interação, na maioria das vezes, era mais eficiente.

Durante as aulas, a coordenadora afirma prestar atenção nas expressões que são utilizadas e as reforça ou as corrige se necessário.

Quando há uma dúvida de um aluno, os multiplicadores reúnem-se em torno dele e tentam resolve-la de forma participativa. Percebe-se com isso que os multiplicadores, além de ensinarem, querem aprender ou reciclar, como disse um deles.

Em uma das ocasiões em que o pesquisador chegou quinze minutos adiantado, pode observar ama discussão entre a coordenadora e dois multiplicadores sobre a utilização do livro/apostila. A coordenadora defendia a importância da utilização do mesmo como uma ferramenta para facilitar a prática em casa. Uma das multiplicadoras disse que, infelizmente, a maioria não treina em casa, por vários motivos, e não necessariamente por falta de entusiasmo. Alguns porque não têm computador disponível em casa; alguns, segundo ela, enfrentam dificuldades porque o filho(a) ou o marido(esposa) tem receio que, por eles terem pouca experiência com o computador, venham a danificá-lo, o que, por sua vez, gera uma insegurança ainda maior. A mesma multiplicadora, comentando sobre a importância da leitura do livro/apostila, disse: "é necessário desmamar um pouco, eles precisam aprender a andarem sozinhos, também, sem precisarem sempre de nós". "Um dos maiores entraves do aprendizado aqui nesta turma é que a maioria não lê a apostila, quer sair logo usando, deduzindo" diz uma das multiplicadoras.

Em uma das aulas em que foi feita a introdução da internet uma das multiplicadores solicitou que todos fechassem os aplicativos abertos e passou a fazer a leitura da apostila, no capítulo da internet. A leitura foi feita em voz alta pela multiplicadora, que fazia pausas para explicar determinados termos como: "o WWW significa uma teia no mundo inteiro, como uma teia de aranha mesmo". Em meio a esta leitura, houve troca de 
experiência com a contratação de serviços de internet. Alguns alunos já têm internet banda larga em casa. No entanto, ainda confundem muito os termos e ainda têm muitas dúvidas. A grande diferença para eles é a questão da internet banda larga permitir que a linha telefônica fique livre e também o fato de a internet discada, segundo a multiplicadora, ser mais cara. Em nenhum momento foi citada a questão da velocidade. $\mathrm{Na}$ apresentação da ferramenta de pesquisa Google ${ }^{\circledR}$, a coordenadora pediu a atenção de todos e fez uma analogia do Google ${ }^{\circledR}$ com uma biblioteca, ou seja, o Google ${ }^{\circledR}$ é uma bibliotecária que ao ser acessada pergunta: em que posso ajudá-lo? E cada link é um livro.

A impressão que se tem é que o aprendizado precisa ser individual, eles assimilam pouco com explorações gerais deste tipo.

\section{A interação: um difícil e empolgante aprendizado}

Baseando-se nas observações discutidas nas seções anteriores, é possível identificar alguns estágios da interação do idoso com a internet, os quais podem ser visualizados na Taxonomia 3.

\begin{tabular}{|c|c|}
\hline \multirow{4}{*}{$\begin{array}{l}\text { Estágios da } \\
\text { Interação }\end{array}$} & Interesse \\
\hline & Desenvolvimento de coordenação psicomotora \\
\hline & Identificação com a máquina \\
\hline & Envolvimento \\
\hline
\end{tabular}

TAXONOMIA 3 - Estágios da Interação

Dos três multiplicadores, existe uma que "puxa" a aula: é quem faz a leitura da apostila e, eventualmente, cria metáforas para explicar determinadas tarefas ou objetos. Uma das primeiras metáforas que o pesquisador ouviu foi a que comparava o editor de textos Word com uma máquina de escrever. Após a abertura do Word, a tarefa executada, seguindo a seqüência da apostila, foi a digitação de um texto. A multiplicadora enfatizou a importância desta atividade dizendo: "gente, nós temos dificuldades de memorização. Por isso, temos de repetir várias vezes a mesma coisa...". Num primeiro momento, a formatação de texto ficou livre para cada um escolher a que quisesse. A maioria escolheu tamanho de fonte maior que 12. Alguns insistiram na caixa alta, embora a apostila indicasse letra normal.

Na digitação dos textos há grande concentração de todos os alunos. Isso possivelmente se dá pela falta de familiaridade deles com o teclado. Uma das alunas citou, em tom de brincadeira: "bem que a minha mãe me dizia para fazer curso de datilografia". A digitação é um processo lento. Foi possível observar que, cada vez que o aluno digita uma palavra, ele olha para o texto digitado para conferir se digitou certo e, na seqüência, olha para a apostila, o que parece uma limitação de memorização.

Em uma das aulas, quando a maioria dos alunos já havia finalizado a digitação do texto, um dos multiplicadores passou para a tarefa de formatação do texto, na qual, segundo a apostila, o título do texto deveria ficar em negrito e o corpo do texto deveria ser posto em outra cor. De 
uma forma geral, não houve muitas dificuldades para esta tarefa. Nesta tarefa, foi evitada a utilização de teclas ou ferramentas de atalho, pois, segundo os multiplicadores, nem sempre estarão disponíveis em todos os computadores. Existe certa dificuldade em relação ao manuseio do mouse, ocorrem freqüentemente cliques em lugares indevidos e qualquer dificuldade no clicar apavora. A coordenadora informou ao pesquisador que a sensibilidade do mouse foi alterada nos computadores do laboratório, para que o "duplo clique" não precise ser tão rápido.

O pesquisador tentou interferir o mínimo possível (apesar de ter sido solicitado várias vezes), para não alterar o fluxo de aprendizagem. Percebeu que, quando as perguntas são feitas para outra pessoa que não o multiplicador, eles se sentem meio que incomodando e tentam justificar as suas dúvidas, o que é menos freqüente quando a interação é feita com o multiplicador ou com um colega. Na maioria das atividades, eventuais erros são inevitáveis e grande parte deles está relacionada à pouca familiaridade com o mouse ou com a sensibilidade deste, e existe certa dificuldade em desfazer algo que foi feito errado. A impressão obtida é que, uma vez efetuado algum comando errado, a primeira reação é abandonar tudo e pedir ajuda.

A maioria dos alunos tem dificuldades com os estrangeirismos. Existem alguns alunos com escolaridade superior e estes apresentam uma facilidade maior. A segunda aula sobre internet iniciou-se com a "abertura" da internet e o acesso ao site do Google ${ }^{\circledR}$. A grande maioria dos computadores não tinha o Google ${ }^{\circledR}$ programado como página inicial, o que causou estranheza dos alunos, obrigando-os a digitarem o endereço completo. Houve algumas dificuldades na digitação do endereço tipo: troca do ponto por vírgula ou deixar espaços entre as palavras. Nesta mesma aula, o pesquisador observou que uma das alunas entrou em uma página que continha vários nomes populares de plantas medicinais, mas, para acessar mais informações, era necessário clicar no nome da planta e, depois, clicar em outro link que ficava abaixo da lista e estava escrito "ver ficha da planta", o que confundiu a aluna e o multiplicador, que acabaram desistindo da página.

Uma das alunas não conseguia visualizar o ícone do Internet Explorer porque o papel de parede da área de trabalho era uma paisagem e confundia um pouco a distinção entre o que era ícone e o que era paisagem. Depois de muito procurar, ela identificou o ícone no rodapé, próximo ao "iniciar", que estava mais "limpo".

Segundo a entrevistada, "a primeira dificuldade está no mouse. Até eles acharem a setinha na tela, têm que treinar bastante. Depois, eles acham que só o curso pode dar suporte integral. Poucos são os que vão para casa ligar o computador verificar sua capacidade. Em seguida, confiam somente na orientação dada. A comodidade também vem junto. Daí resulta na seguinte dificuldade: em saber como procurar assuntos de interesse. Há também a questão da digitação, pois poucos são os que trabalharam com máquina de escrever". Desta forma, identifica-se, na Taxonomia 4, as principais dificuldades. 


\begin{tabular}{|l|l|l|}
\hline \multirow{4}{*}{$\begin{array}{c}\text { Tipos de } \\
\text { Dificuldades }\end{array}$} & Motora & \multicolumn{1}{c|}{ Digitar } \\
\cline { 2 - 2 } & \multicolumn{2}{|c|}{$\begin{array}{l}\text { Trabalhar com o } \\
\text { mouse }\end{array}$} \\
\cline { 2 - 3 } & Memorização \\
\cline { 2 - 3 } & Visual \\
\cline { 2 - 3 } & Linguagem & \\
\cline { 2 - 3 }
\end{tabular}

Taxonomia 4 - Tipos de dificuldades

Antes mesmo do primeiro contato e em meio ao processo de interação, surgem alguns medos, gerados pelo desconhecimento e pela própria desconfiança dos que rodeiam o idoso, mais especificamente os familiares, como identificado na primeira entrevista com a multiplicadora, onde ela discorre: "(...) Eu tinha computador em casa, mas não era meu. Então, tu não pode mexer aí, tu não pode mexer, vai deletar tudo.. não, nem ligar, não mexe. Então, aquilo me criou um... eu entrei em pânico. Como que eu não posso mexer? Todo mundo mexe. Como que eu não posso? Fui fazer o curso, mas também não podia mexer, não podia treinar praticar em casa, porque tinha os trabalhos deles. Apesar de eu estar... mas tu é uma aprendiz. Então aí eu parei tudo, uma que eu tinha problema com os pais doentes, aí eu deixei (...)". Observa-se nesta passagem que existem fatores da própria condição do idoso, agravadas pela pouca receptividade familiar no que tange à confiabilidade. A alta sensibilidade do idoso interfere significativamente na interação, podendo ao mesmo tempo potencializar o interesse ou desestimular, através da geração de medos. Um outro receio que está presente na interação entre idoso e internet é o referente a compras pela rede. Os que o fazem, não se sentem seguros em dar dados pessoais via internet, como se observa nesta passagem da entrevista: "(...) eu não faço (compras pela internet) porque eu não gosto de dar meus dados nem muito menos movimentação de conta bancária. Este meu instrutor até me orientou a não fazer, por causa deste problema de hackers né? Disseram que o Banco do Brasil é seguro, que agora o Itaú tem um chip.... tem um não sei que.... que evita que entre hacker, mas, na dúvida, eu não faço. Então, eu não utilizo, eu gosto de ver, gosto de pesquisar, de procurar (...). Só compro em lojas daqui, que eu já conheço (...) e só se eles me fornecerem o número da conta (deles) para eu depositar, eu não iria fornecer nenhum dado. Eu deposito, depois eles me mandam o produto."

Existe por parte de alguns multiplicadores certo medo de não saber - que fazer em determinada situação em que são solicitados pelos aprendizes. A Taxonomia 5 cita os principais medos identificados. 


\begin{tabular}{|l|l|}
\hline \multirow{4}{*}{ Tipos de Medo } & Danificar a máquina \\
\cline { 2 - 2 } & Apagar arquivos \\
\cline { 2 - 2 } & Fornecer dados pessoais \\
\hline determinada situação \\
\cline { 2 - 2 } & Invasão da privacidade de outros \\
\cline { 2 - 2 } & Instalar vírus no computador \\
\hline
\end{tabular}

TAXONOMIA 5 - Tipos de medos

A comunicação via internet é vista pelos idosos consultados como uma forma de comunicação menos fria, quando comparada ao telefone, uma vez que a internet permite a visualização via webcam e outras formas de expressão como os chamados emocions do $\mathrm{MSN}^{\circledR}$, que são figurinhas que substituem palavras ou expressões. Durante a segunda entrevista, que foi realizada via $\mathrm{MSN}^{\circledR}$, a entrevistada usou várias vezes este recurso expressivo. Quando questionada sobre o significado destas figuras ou "animações" numa conversa, a resposta foi a seguinte: " no início, achei engraçado e fiquei curiosa em como inserir tais "figurinhas". Agora que aprendi, e na continuidade, achei um pouco brega (...) Dão um sentido curioso para quem ainda não sabe utilizar e tornam a conversa mais agradável."

\section{Considerações finais}

A cada dia a internet vem ganhando mais espaço em toda a sociedade. No entanto, a interação de determinados grupos ou micro culturas tende a ser diferenciada, pelos mais diversos motivos, como é o caso dos idosos, que possuem, além de uma gama de limitações, outros interesses e outras formas de encarar a internet, tanto por sua condição atual como por suas histórias de vida. Desta forma, o presente estudo concentrou-se em acompanhar a interação do idoso com a internet, abordando seus estágios iniciais, a descoberta dos interesses, a adaptação e as peculiaridades do aprendizado, as dificuldades e os medos gerados neste processo. Os interesses são predominantemente de cunho social e familiar, evidenciando a internet para o idoso como um canal de aproximação com os filhos e como forma alternativa de informação e diversão. O aprendizado é uma parte fundamental para manter o interesse e responder às expectativas. $O$ estudo mostrou que o modelo de aprendizagem por pares é capaz de acompanhar o desenvolvimento do idoso em sua interação com a internet, além de criar um ambiente social de companheirismo e troca de experiências. As dificuldades são decorrentes de várias limitações, as quais inevitavelmente surgem com o 
passar da idade como dificuldades motoras, de memorização e visual, além de dificuldades com a linguagem computacional. Os medos surgem da própria falta de conhecimento, do desincentivo e, muitas vezes, da falta de apoio familiar. Sendo assim, o estudo observou algumas das peculiaridades da interação do idoso com a internet em sua fase inicial, indicando, desta forma, futuras abordagens aprofundadas neste campo, como, por exemplo, os reflexos da internet com o desenvolvimento social do idoso, suas vantagens e desvantagens, ou ainda a comunicação virtual entre eles e com os demais.

\section{Referências}

DIXON, J. M. Predicting seniors' use of cyberspace. New York: Garland, 1997.

KANAYAMA, T. Ethnographic research on the experience of japanese elderly people online. New Media \& Society, v. 5, n. 2, p. 267-288, 2003.

MCCURDY, D. W.; SPRADLEY, J. P.; SHANDY, D. J. The Cultural Experience. 2. ed. Long Grover-IL-USA: Waveland Press, 2005. p. 03-41.

SALES, M. B. Modelo multiplicador utilizando a aprendizagem por pares focado no idoso. 138f. Tese (Doutorado em Engenharia e Gestão do Conhecimento) - Pós- Graduação em Engenharia e Gestão do Conhecimento, Universidade Federal de Santa Catarina - UFSC, Florianópolis, 2007.

TAYLOR S. J., BOGDAN, R. Introduction to qualitative research methods: a guidebook and resource. New York: John Wiley \& Sons, 1997. p. 24-43.

THORNTON, J. E. Educational activities for older adults: handbook of the Society for Learning in Retirement. 2005. Disponível em: <http://www.slrkelowna.ca/handbook.html >. Acesso em: 18 jun. 2008.

ORGANIZAÇÃO DAS NAÇÕES UNIDAS PARA A EDUCAÇÃO, A CIÊNCIA E A CULTURA (UNESCO). Manual for media trainers a learner-centred approach. Disponível em: <http://www.unesco.org/webworld/publications/media trainers/manual.pdf $>$.

Acesso em: 22 jun 2008.

VAN MAANEN, J. Playing back the tape: early days in the field. In: SHAFFIR, W. B.; STEBBINS, d R. A. Experiencing fieldwork: an inside view of qualitative research. Park, CA: Sage Publications, 1991. p. 31-42.

VYGOTSKY, L. S. A formação social da mente: desenvolvimento dos processos mentais superiores. São Paulo: Martins Fontes, 1984.

WRIGHT, K. Computer-mediated Social Support, Order Adults, and Coping. Journal of Communication, v. 50, n. 3, p.100-18, 2000. 